in vivo $35: 1083-1089(2021)$

doi:10.21873/invivo.12353

\title{
Prognostic Evaluation of the Site of Invasion in Pathological Stage T3a Renal Cell Carcinoma
}

\author{
GU-SHUN LAI ${ }^{1}$, JIAN-RI LI ${ }^{2,3,4}$, SHIAN-SHIANG WANG ${ }^{2,3,5}$, CHUAN-SHU CHEN $^{2,3}$, CHUN-KUANG YANG $^{2}$, \\ SHENG-CHUN HUNG ${ }^{2,3}$, CHEN-LI CHENG ${ }^{2,3}$, YEN-CHUAN OU ${ }^{3,6}$ and KUN-YUAN CHIU ${ }^{2,5}$ \\ ${ }^{1}$ Division of Urology, Department of Surgery, Chiayi Branch, \\ Taichung Veterans General Hospital, Chiayi, Taiwan, R.O.C.; \\ ${ }^{2}$ Division of Urology, Department of Surgery, Taichung Veterans General Hospital, Taichung, Taiwan, R.O.C.; \\ ${ }^{3}$ Institute of Medicine, Chung Shan Medical University, Taichung, Taiwan, R.O.C.; \\ ${ }^{4}$ Department of Medicine and Nursing, Hungkuang University, Taichung, Taiwan, R.O.C.; \\ ${ }^{5}$ Department of Applied Chemistry, National Chi Nan University, Nantou, Taiwan, R.O.C.; \\ ${ }^{6}$ Department of Urology, Tung's Taichung MetroHarbor Hospital, Taichung, Taiwan, R.O.C.
}

\begin{abstract}
Background/Aim: To investigate the prognostic values of fat invasion (FI) and renal vein invasion (RVI) in pT3a renal cell carcinoma $(R C C)$, as single factors or concomitant presence. Patients and Methods: We retrospectively reviewed the data of 173 patients who underwent radical or partial nephrectomy for RCC in our Institution. Results: At a median follow-up time of 48 months, patients with RVI showed significantly increased risk of disease recurrence and worse cancer-specific survival (CSS) when compared to those with FI ( $p=0.007$, $p=0.022$, respectively). Having combined $R V I$ and FI did not show inferior prognosis compared to those with RVI only. In multivariable analysis, RVI was an independent factor for disease recurrence $(H R=2.06,95 \% \quad C I=1.10$ 3.87, $p=0.024)$ and CSS $(H R=2.46,95 \% C I=1.01-6.0$, $p=0.048)$. Conclusion: For patients with T3a renal tumors, $R V I$ was associated with inferior prognosis compared to those with FI.
\end{abstract}

Tumor staging is a process for determining the severity of the primary tumors and the condition of its extension. It helps predict prognosis, make disease management plans and

This article is freely accessible online.

Correspondence to: Kun-Yuan Chiu, Division of Urology, Department of Surgery, Taichung Veterans General Hospital, No. 1650, Sec. 4, Taiwan Boulevard, Taichung 407, Taiwan, R.O.C. Tel: +886 423592525 \#5121, Fax: +886 423593160, e-mail: powerxyz17@gmail.com

Key Words: Fat invasion, pathological T3a, prognosis, renal cell carcinoma, renal vein invasion. formulate surveillance strategies. In the recent $8^{\text {th }}$ edition of the American Joint Committee on Cancer (AJCC) tumornode-metastasis (TNM) staging system, T3a renal cell carcinoma (RCC) was defined as a tumor with renal vein invasion (RVI), pelvicalyceal system invasion (PSI), perirenal fat invasion (PFI) or sinus fat invasion (SFI) (1).

Theoretically, patients with renal tumors at the same stage should experience similar disease recurrence and survival rates. However, previously published literature reported that the oncologic outcomes regarding the different extrarenal extension sites in pathological stage T3a RCC are heterogeneous and further studies to investigate these differences were necessary (2-9).

In the present study, we aimed to evaluate the impact surrounding different sites of extrarenal invasion on one's prognosis in pT3a RCC, as well as the effect of tumor size for these patients.

\section{Patients and Methods}

Following the Institutional Review Board's approval, a retrospective chart review of patients who had undergone radical or partial nephrectomy for renal tumors between 2000 and 2018 was performed at our Hospital. Renal tumors diagnosed as pathological stage T2 and T3 RCC pathologically were included. All patients received pre-operative, cross-sectional imaging with computed tomography (CT) or magnetic resonance imaging (MRI) for accurate tumor staging. Regional lymph node dissection was performed if the patient was found to have enlarged lymph nodes discovered during preoperative image studies. Patients with metastatic disease and inadequate data for analysis were excluded from analysis.

According to tumor stages and site of invasion, we divided patients into 4 groups: T2, T3a with fat invasion (FI), T3a with RVI and $\mathrm{T} 3 \mathrm{~b}+\mathrm{T} 3 \mathrm{c}$. The $\mathrm{T} 2$ and $\mathrm{T} 3 \mathrm{~b}+\mathrm{T} 3 \mathrm{c}$ groups were used to compare and investigate if the prognosis of the T3a cohorts were similar to the groups below or above the T3a. 
Table I. Patient demographics, pathological characteristics and outcomes.

\begin{tabular}{|c|c|c|c|c|c|}
\hline & $\begin{array}{c}\mathrm{T} 2 \\
(\mathrm{n}=47)\end{array}$ & $\begin{array}{l}\text { T3a FI } \\
(\mathrm{n}=71)\end{array}$ & $\begin{array}{c}\text { T3a RVI } \\
(\mathrm{n}=36)\end{array}$ & $\begin{array}{c}\mathrm{T} 3 \mathrm{~b}+\mathrm{T} 3 \mathrm{c} \\
(\mathrm{n}=19)\end{array}$ & $p$-Value \\
\hline Age, years (IQR) & $52(41-69)$ & $60(51-72)$ & $63.5(53.8-72.8)$ & $55(40-73)$ & 0.145 \\
\hline Male Gender, n (\%) & $25(53.1)$ & $46(64.8)$ & $26(72.2)$ & $11(57.9)$ & 0.319 \\
\hline Follow up, months (IQR) & $71(31-112)$ & $51(24-72)$ & $45.5(17-78)$ & $18(12-33)$ & $<0.001^{*}$ \\
\hline Tumor size, $\mathrm{cm}$ (IQR) & $8.5(7.6-10)$ & $6.5(4.5-9)$ & $7(5.8-9)$ & $8(6-10)$ & $<0.001^{*}$ \\
\hline Fuhrman grade, $\mathrm{n}(\%)$ & & & & & 0.176 \\
\hline 1 & 0 & 1 & 0 & 0 & \\
\hline 2 & 12 & 25 & 8 & 4 & \\
\hline 3 & 16 & 25 & 10 & 7 & \\
\hline 4 & 4 & 14 & 7 & 4 & \\
\hline unknown & 15 & 6 & 11 & 4 & \\
\hline \multicolumn{6}{|l|}{ Histology, n (\%) } \\
\hline Clear & 24 & 53 & 26 & 9 & $<0.001^{*}$ \\
\hline Papillary & 5 & 5 & 0 & 5 & \\
\hline Chromophobe & 15 & 4 & 3 & 0 & \\
\hline Others & 3 & 9 & 7 & 5 & \\
\hline Necrosis, n (\%) & $22(46.8)$ & $23(32.4)$ & $11(30.6)$ & $12(63.2)$ & $0.042 *$ \\
\hline Sarcomatoid festures, n (\%) & $1(2.1)$ & $6(8.4)$ & $2(5.6)$ & $5(26.3)$ & $0.011 *$ \\
\hline LVI, n (\%) & $4(8.5)$ & $13(18.3)$ & $18(50)$ & $14(73.7)$ & $<0.001^{*}$ \\
\hline Margin Positive, n (\%) & 0 & $2(2.8)$ & $4(11.1)$ & $1(5.2)$ & 0.073 \\
\hline Partial Nephrectomy, n (\%) & $5(10.6)$ & $10(14.0)$ & $1(2.8)$ & 0 & $0.021 *$ \\
\hline Recurrence, n (\%) & $14(27.7)$ & $21(28.2)$ & $19(50.0)$ & $1(68.4)$ & $0.003 *$ \\
\hline Local recurrence & 0 & 3 & 1 & 0 & \\
\hline Distant metastasis & 13 & 16 & 14 & 12 & \\
\hline $\begin{array}{l}\text { Local recurrence+ } \\
\text { distant metastasis }\end{array}$ & 0 & 1 & 3 & 1 & \\
\hline $\mathrm{CSS}, \mathrm{n}(\%)$ & $43(91.5)$ & $62(83.8)$ & $25(69.4)$ & $13(68.4)$ & $0.013 *$ \\
\hline OS, $\mathrm{n}(\%)$ & $43(91.5)$ & $55(77.5)$ & $23(63.8)$ & $12(63.2)$ & $0.011 *$ \\
\hline
\end{tabular}

CSS: Cancer specific survival; FI: fat invasion; IQR: interquartile range; LVI: lymphovascular invasion; OS: overall survival; RVI: renal vein invasion. *Statistically significant $p$-values.

Patient demographics, clinicopathological and surgical characteristics were obtained and evaluated. Continuous variables were expressed as medians and interquartile range (IQR). The Kruskal-Wallis test was used to compare the means of continuous variables, while the Chi-square test was used to compare categorical variables. Recurrence free survival (RFS) and cancer specific survival (CSS) were estimated using the Kaplan-Meier method and compared using log-rank tests. Univariable and multivariable Cox proportional hazard regression models were used to identify the clinical and pathologic factors for prognosis. A $p$-value $<0.05$ was considered statistically significant, and all analyses were performed using SPSS software (version 19.0; SPSS Inc., Chicago, IL, USA).

\section{Results}

A total of 173 patients were included in the study. Patients were divided into 4 groups: T2 $(n=47)$, T3a with FI $(n=71)$, T3a with RVI $(n=36)$ and T3b+T3c $(n=19)$. Demographics, clinicopathological features and oncologic outcomes between the 4 groups were compared and are presented in Table I.

The median follow-up time was 48 months, during which 67 patients $(38.7 \%)$ experienced disease recurrence at a median (IQR) of 10 (6-30) months, with patients in the T3a with RVI and $\mathrm{T} 3 \mathrm{~b}+\mathrm{T} 3 \mathrm{c}$ groups having a significantly higher risk of disease recurrence than the other 2 groups $(p=0.003)$. Thirty patients $(17.3 \%)$ died from disease progression at a median follow-up time (IQR) of 20.5 (14.5-37.3) months, with T3a with RVI and T3b+T3c groups having a significantly reduced cancer specific survival rate $(p=0.013)$.

Survival analysis using the Kaplan-Meier method is shown in Figure 1. RFS was worst at the T3b+T3c group. The T3a with RVI group experienced significantly inferior RFS when compared to the T3a with FI group $(p=0.007)$. Additionally, RFS for the T3a with FI group was similar to that of the T2 group ( $p=0.699$ ). Similar results were also observed regarding CSS. The worst CSS was found in the $\mathrm{T} 3 \mathrm{~b}+\mathrm{T} 3 \mathrm{c}$ group, while the T3a with RVI group displayed significantly reduced CSS when compared to the T3a with FI group $(p=0.022)$. The 5year RFS was $74.8 \%$ for T2, $67.7 \%$ for T3a with FI, $42.2 \%$ for T3a with RVI and $14.1 \%$ for T3b+T3c. The 5-year CSS was $92.9 \%$ for T2, $85.6 \%$ for T3a with FI, $68.2 \%$ for T3a with RVI and $60.7 \%$ for $\mathrm{T} 3 \mathrm{~b}+\mathrm{T} 3 \mathrm{c}$. 

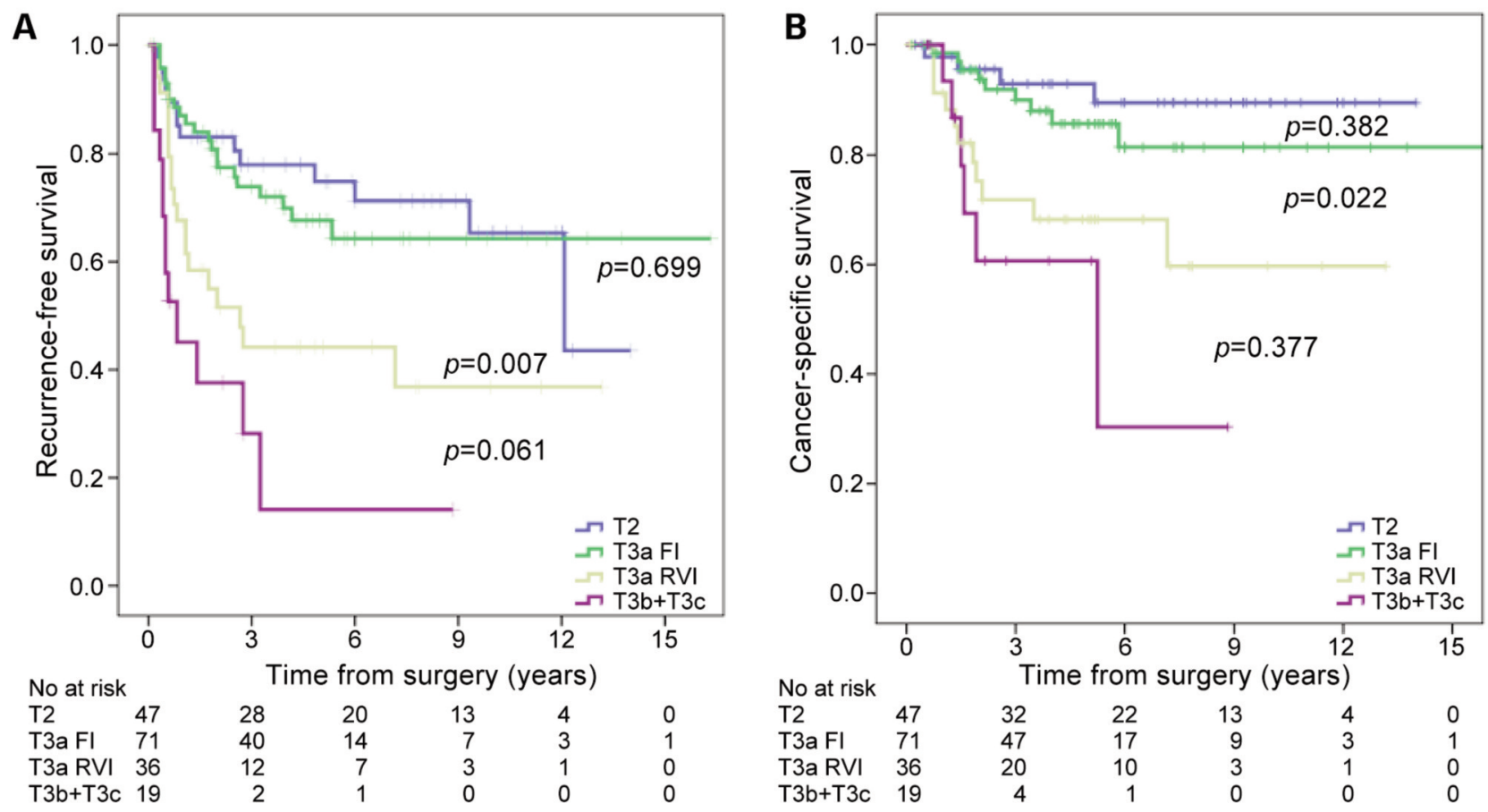

Figure 1. Recurrence free survival (A) and cancer specific survival (B) among the 4 groups: T2, T3a with fat invasion (FI), T3a with renal vein invasion (RVI) and T3b+T3c.

Patients with renal tumors having both renal vein invasion and fat invasion had similar RFS and CSS when compared to those with renal vein invasion only (Figure 2). When taking tumor size into consideration, we found that renal tumors greater than $7 \mathrm{~cm}$ with fat invasion showed poor oncologic outcomes in terms of RFS and CSS than their T2 counterparts (Figure 3).

Evaluation of predictive factors for RFS and CSS using the Cox proportional hazard model is delineated in Table II. Based upon univariable analysis, the T3a with RVI and $\mathrm{T} 3 \mathrm{~b}+\mathrm{T} 3 \mathrm{c}$ group were associated with a higher risk of tumor recurrence [T3a with RVI: Hazard ratio $(\mathrm{HR})=2.28$, 95\% Confidence interval $(95 \% \mathrm{CI})=1.22-4.27, p=0.01$; $\mathrm{T} 3 \mathrm{~b}+\mathrm{T} 3 \mathrm{c}: \mathrm{HR}=4.65,95 \% \mathrm{CI}=2.26-9.52, p<0.01]$ and disease related death (T3a with RVI: $H R=2.67,95 \%$ $\mathrm{CI}=1.11-6.46, \quad p=0.029 ; \quad \mathrm{T} 3 \mathrm{~b}+\mathrm{T} 3 \mathrm{c}: \quad \mathrm{HR}=5.10,95 \%$ $\mathrm{CI}=1.76-14.65, p=0.002)$. Based upon multivariable analysis adjusted for grade, size, necrosis and sacromatoid features, the T3a with RVI and T3b+T3c groups were associated with both worse RFS (T3a with RVI: HR=2.06, 95\% CI=1.1-3.87, $p=0.024 ; \mathrm{T} 3 \mathrm{~b}+\mathrm{T} 3 \mathrm{c}: \mathrm{HR}=3.6,95 \%$ $\mathrm{CI}=1.74-7.45, p<0.001)$ and $\mathrm{CSS}$ (T3a with RVI: $\mathrm{HR}=2.46,95 \% \mathrm{CI}=1.01-6.0, p=0.048 ; \mathrm{T} 3 \mathrm{~b}+\mathrm{T} 3 \mathrm{c}: \mathrm{HR}=4.4$, $95 \% \mathrm{CI}=1.41-13.72, p=0.011)$, when compared to the $\mathrm{T} 3 \mathrm{a}$ with FI group.

\section{Discussion}

In the present study, we analyzed the oncological outcomes of pT3a RCC according to various sites of extrarenal invasion and found that patients with RVI experienced an increased rate of tumor recurrence and cancer related death when compared to those with FI. Based upon the multivariable analysis, RVI was a predictive factor for tumor recurrence and survival.

According to the $8^{\text {th }}$ AJCC TNM staging system (1), stage T3a RCC comprised various patterns of extrarenal extension, including SFI, PFI, PSI and RVI, amongst which patients should theoretically show similar prognosis. However, previously published literature has reported that the oncological outcomes of these pT3a RCC patients were heterogeneous, and the impact of different sites of extrarenal invasion was a subject of debate. RVI-only and FI-only tumors carried similar prognosis according to previous studies by Baccos el al. (9) and Shah et al. (10). Novara and his colleagues (11) reported that better prognosis was observed in the RVI group than the FI group. On the contrary, Part et al. (8) and Jung et al. (12) found that patients with RVI experienced poor survival rate and higher rate of disease recurrence. Our study also found that patients with RVI demonstrated poorer prognosis than did the FI 
A

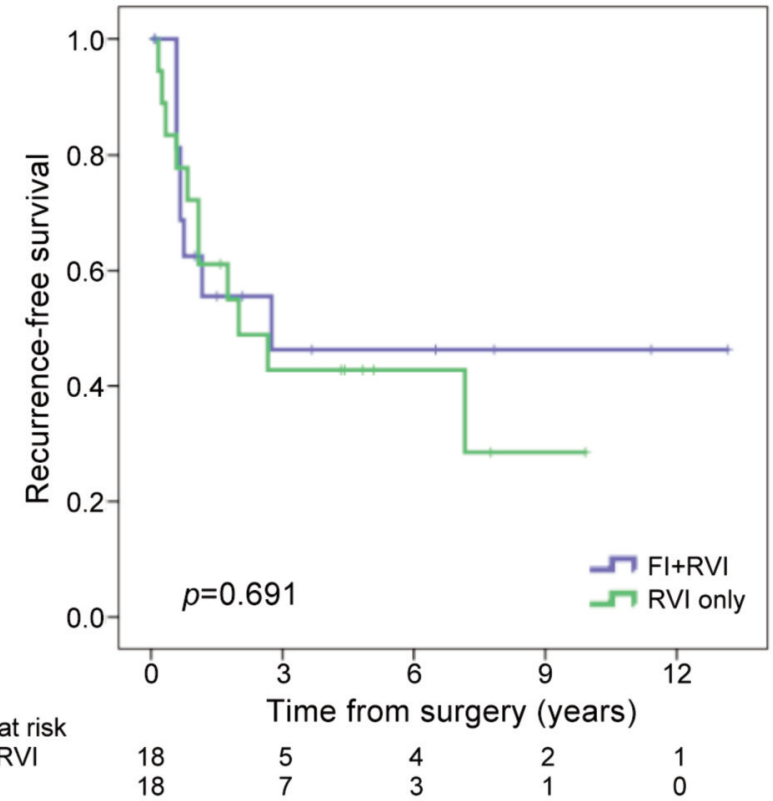

RVI

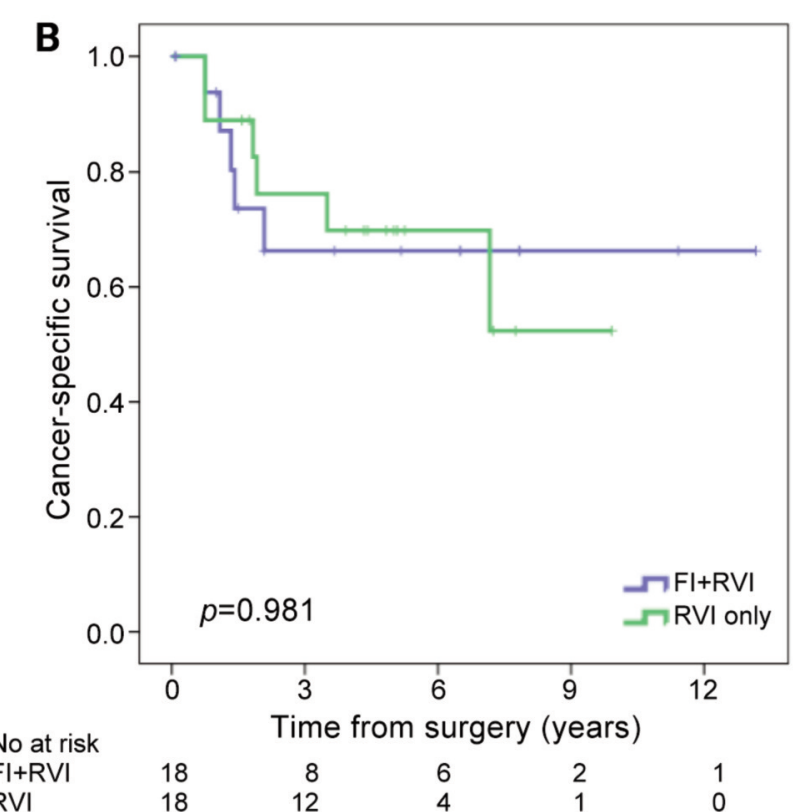

Figure 2. Compa (FI) groups.

group. The conflicting results which occurred among these studies may be attributed to the differences in tumor size, pathologic examination and small sample sizes.

The impact of SFI and PFI on prognosis, according to previous studies has been controversial (2-6). Poon et al. observed that both the SFI and PFI have a comparable influence on oncologic outcomes (7). The present study also found that there was no significant difference in survival and tumor recurrence between those patients with SFI and PFI. Thus, both of the parameters were combined into the FI group in the present study.

Shah et al. (10) reported that isolated SFI, PFI or RVI carry similar prognostic impacts and the presence of multiple patterns of extrarenal invasion was associated with a higher risk of disease recurrence and cancer related death. However, the present study found that patients with combined FI+RVI are given a similar prognosis as the patients with RVI-only tumors (Figure 2). This may be attributed to that the more aggressive nature of RVI and it overweighed the influence of FI on prognosis. Therefore, patients with FI+RVI were categorized and placed in the RVI group in our study.

Conventional RVI was considered for primary tumors with gross extension to the renal vein or its segmental branches. However, an analysis conducted by Part et al. (8) revealed that microscopic renal vein wall invasion was a prognostic factor for disease recurrence and cancer related death. In the series by Zini et al. (13) and Faba et al. (14) also reported that microscopic renal vein wall invasion was an independent prognostic indicator of inferior oncologic outcomes.
Microscopic renal vein wall invasion is analogous to renal tumors with vena cava wall invasion, which is included in stage T3c in the $8^{\text {th }}$ AJCC staging system (1), and demonstrates adverse pathologic features. Our study revealed that patients with $\mathrm{T} 3 \mathrm{~b}$ and $\mathrm{T} 3 \mathrm{c}$ renal tumors experienced inferior RFS and CSS, although neither reached statistical significance, when compared to the T3a with RVI group. The discrepancy of these results can be explained by that the fact that the RVI group in the present study included patients with either renal vein thrombus or microscopic renal vein wall invasion.

The prognostic importance regarding tumor size and FI is controversial and many studies have investigated the differences between these factors. Previous literature has reported that patients with pT3a RCC $<4 \mathrm{~cm}$ experienced similar outcomes when compared to those with pT1a RCC $(15,16)$. Studies performed by Gilbert et al. (17) suggested that the patients with pT3a and pT1-2 RCC experienced comparable 5-year RFS rates. However, several studies have demonstrated a worse prognosis in patients with pT3a RCC upstaging from clinical stage T1a renal tumors $(18,19)$. In the present study, we found that RFS and CSS of patients with FI renal tumors were not different from that of $\mathrm{pT} 2$. This may result from tumor size having an impact on prognosis for FI patients, and our cohort included patients with renal tumor size smaller and larger than $7 \mathrm{~cm}$. In fact, a subgroup analysis in the present study revealed that patients with FI RCC $>7 \mathrm{~cm}$ had significantly inferior 5year RFS and CSS than patients in the pT2 group (RFS: FI $v s$. T2 $42.1 \%$ vs. $76.8 \%, p=0.02$; CSS: FI vs. T2 70.1\% vs. $95.4 \%$, 
A

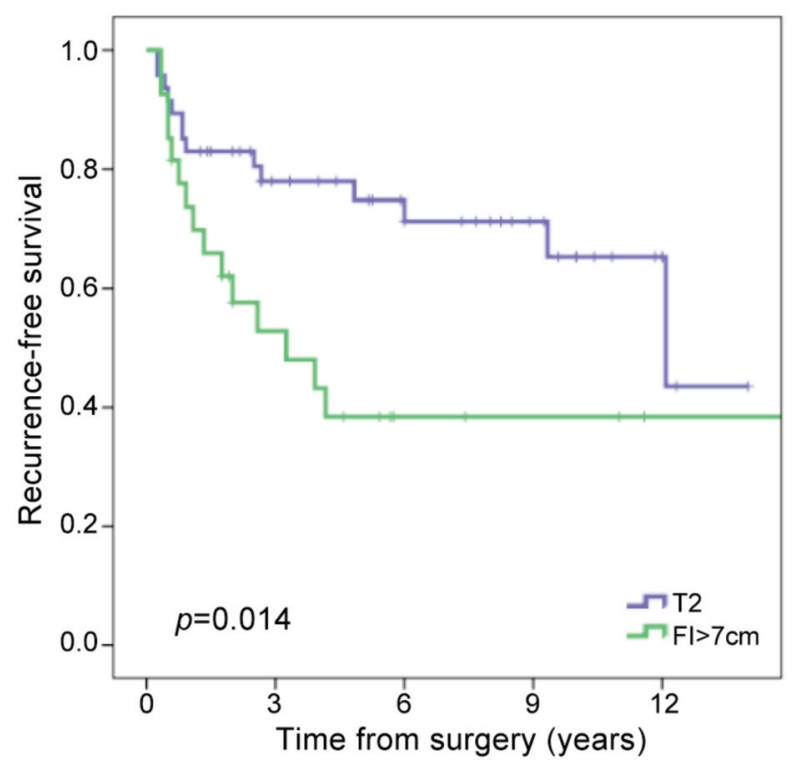

B

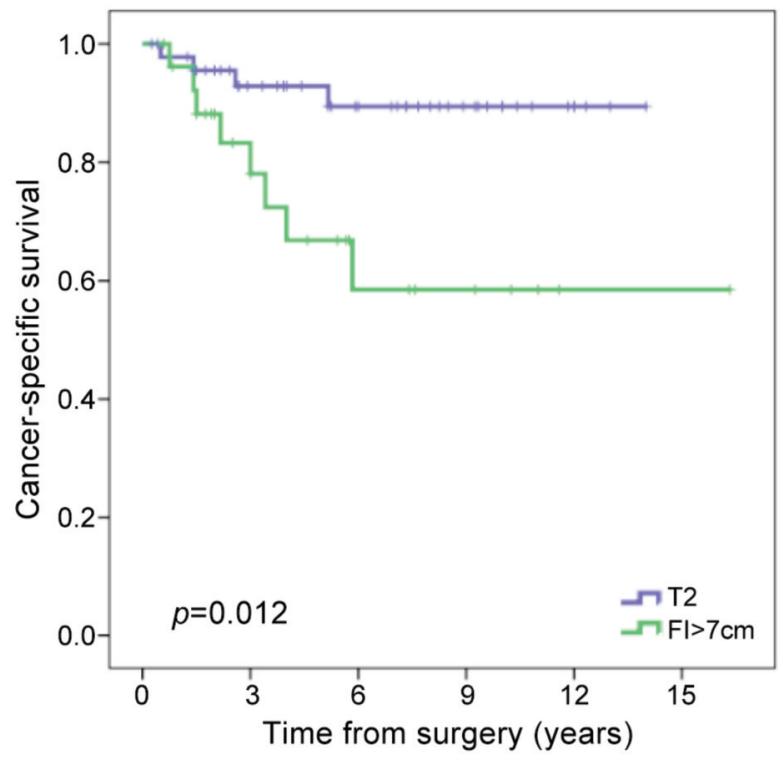

No at risk

$\begin{array}{llrrrrr}\text { T2 } & 47 & 32 & 23 & 13 & 5 & 0 \\ \text { FI }>7 \mathrm{~cm} & 27 & 16 & 7 & 5 & 1 & 1\end{array}$
No at risk
FI+RVI

RVI

$\begin{array}{ll}47 & 28 \\ 27 & 11\end{array}$

\section{1}

13
3

5
1

$\mathrm{Fl}>7 \mathrm{~cm}$

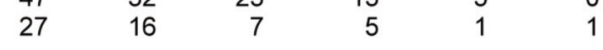

Figure 3. Comparison of recurrence-free survival (A) and cancer-specific survival (B) between T2 and T3a with fat invasion (FI) greater than $7 \mathrm{~cm}$ groups.

$p=0.001)$. These results were compatible with the researches performed by Jeon et al. (20) and Yoo et al. (21), which showed that FI was an independent prognostic factor for RFS and CSS in pT3a tumors larger than $7 \mathrm{~cm}$.

Precise tumor staging and risk stratification are cornerstones for evaluating patients' prognosis and deciding postoperative follow-up protocol. With increased interest in neoadjuvant and adjuvant systemic therapy for RCC in recent years, it is important to stratify patients accurately (22-24). In addition to the influence of different extrarenal extension sites on oncologic outcomes (2-9), Jang et al. reported that high minichromosome maintenance (MCM) gene expression level was a predictor of tumor progression and metastasis (25). In the present study, we showed that patients with RVI experienced inferior outcomes compared to those with FI, and that most of disease recurrence involved distant metastasis. This further emphasized the role of adjuvant systemic therapy for advanced RCC, as well as accurate patient classification.

Several limitations exist in the present study. The retrospective data collection and limited sample sizes were subject to inherent biases. The present study included various histological subtypes of RCC and different surgical approaches, which may influence the accuracy when evaluating results. Furthermore, the data of this research spanned from 2000 to 2018 , and a lack re-review of the pathological specimens by a urological pathologist also resulted in biases.
Table II. Cox proportional hazard regression models for prognosis.

\begin{tabular}{|c|c|c|c|c|}
\hline & $\begin{array}{c}\text { Univariable } \\
\text { recurrence HR } \\
\quad(95 \% \mathrm{CI})\end{array}$ & $p$-Value & $\begin{array}{c}\text { Multivariable } \\
\text { recurrence HR } \\
\quad(95 \% \mathrm{CI})\end{array}$ & $p$-Value \\
\hline $\mathrm{T} 2$ & $0.88(0.44-1.28)$ & 0.7 & $0.68(0.33-1.38)$ & 0.285 \\
\hline T3a FI & Reference & & Reference & \\
\hline T3a RVI & $2.28(1.22-4.27)$ & $0.01 *$ & $2.06(1.10-3.87)$ & $0.024 *$ \\
\hline \multirow[t]{2}{*}{$\mathrm{T} 3 \mathrm{~b}+\mathrm{T} 3 \mathrm{c}$} & $4.65(2.26-9.52)$ & $<0.001 *$ & $3.60(1.74-7.45)$ & $<0.001^{*}$ \\
\hline & $\begin{array}{c}\text { Univariable } \\
\text { CSS HR }(95 \% \mathrm{CI})\end{array}$ & & $\begin{array}{c}\text { Multivariable } \\
\text { CSS HR }(95 \% \text { CI })\end{array}$ & \\
\hline $\mathrm{T} 2$ & $0.59(0.18-1.94)$ & 0.387 & $0.52(0.16-1.71)$ & 0.279 \\
\hline T3a FI & Reference & & Reference & \\
\hline T3a RVI & $2.67(1.11-6.46)$ & $0.029 *$ & $2.46(1.01-6.0)$ & $0.048^{*}$ \\
\hline $\mathrm{T} 3 \mathrm{~b}+\mathrm{T} 3 \mathrm{c}$ & $5.10(1.76-14.65)$ & $0.002 *$ & $4.40(1.41-13.72)$ & $0.011 *$ \\
\hline
\end{tabular}

CI: Confidence interval; CSS: cancer specific survival; FI: fat invasion; HR: hazard ratio; RVI: renal vein invasion. $*$ Statistically significant $p$ values. Adjusted for grade, size, necrosis and sacromatoid features.

In conclusion, the present study reveals that patients with RCC extending to renal veins experience worse RFS and CSS than patients with RCC invading to sinus fat or perinephretic fat. RCC with combined RVI and FI did not show inferior prognosis compared to those with isolated RVI. Tumor size should be taken into consideration when evaluating the prognostic impact of pT3a RCC. These findings assist in the 
stratification of patients with pT3a RCC when providing a prognosis and deciding upon follow-up protocol, as well as implementing the use of adjuvant therapy.

\section{Conflicts of Interest}

There are no conflicts of interest.

\section{Authors' Contributions}

The study was designed by GSL and JRL. Data were provided and analyzed by JRL, SSW, CSC, CKY, SCH, CLC, YCO and KYC. The article was drafted by GSL. All Authors have read and approved the manuscript for publication.

\section{References}

1 Amin MB, Greene FL, Edge SB, Compton CC, Gershenwald JE, Brookland RK, Meyer L, Gress DM, Byrd DR and Winchester DP: The eighth edition AJCC cancer staging manual: continuing to build a bridge from a population-based to a more "personalized" approach to cancer staging. CA Cancer J Clin 67(2): 93-99, 2017. PMID: 28094848. DOI: 10.3322/caac.21388

2 Bedke J, Buse S, Pritsch M, Macher-Goeppinger S, Schirmacher P, Haferkamp A and Hohenfellner M: Perinephric and renal sinus fat infiltration in pT3a renal cell carcinoma: possible prognostic differences. BJU Int 103(10): 1349-1354, 2009. PMID: 19076147. DOI: 10.1111/j.1464-410X.2008.08236.x

3 Zhang Z, Yu C, Velet L, Li Y, Jiang L and Zhou F: The difference in prognosis between renal sinus fat and perinephric fat Invasion for pT3a Renal Cell Carcinoma: A Meta-Analysis. PLoS One 11(2): e0149420, 2016. PMID: 26891054. DOI: 10.1371/journal.pone. 0149420

4 Kresowik TP, Johnson MT and Joudi FN: Combined renal sinus fat and perinephric fat renal cell carcinoma invasion has a worse prognosis than either alone. J Urol 184(1): 48-52, 2010. PMID: 20478592. DOI: 10.1016/j.juro.2010.03.010

5 Mouracade P, Dagenais J, Chavali JS, Kara O, Nelson RJ, Maurice MJ, Reese J, Rini BI and Kaouk JH: Perinephric and sinus fat Invasion in stage pT3a tumors managed by partial nephrectomy. Clin Genitourin Cancer 16(5): e1077-e1082, 2018. PMID: 28818550. DOI: 10.1016/j.clgc.2017.07.019

6 Guo S, Liu Z, Li X, Yao K, Dong P, Chen D, Liao C, Long Z, Wang Y, Zhou F, He X and Liu Z: The prognostic value of the site of invasion in T3aNOM0 clear cell renal cell carcinoma. Urol Oncol 37(5): 301.e11-301.e17, 2019. PMID: 30704960. DOI: 10.1016/j.urolonc.2019.01.019

7 Poon SA, Gonzalez JR, Benson MC and McKiernan JM: Invasion of renal sinus fat is not an independent predictor of survival in pT3a renal cell carcinoma. BJU Int 103(12): 16221625, 2009. PMID: 19154464. DOI: 10.1111/j.1464-410X. 2008.08239.x

8 Park M, Shim M, Kim M, Song C, Kim CS and Ahn H: Prognostic heterogeneity in T3aNOM0 renal cell carcinoma according to the site of invasion. Urol Oncol 35(7): 458.e17458.e22, 2017. PMID: 28476528. DOI: 10.1016/j.urolonc. 2016.05.019

9 Baccos A, Brunocilla E, Schiavina R, Borghesi M, Rocca GC, Chessa F, Saraceni G, Fiorentino M and Martorana G: Differing risk of cancer death among patients with pathologic T3a renal cell carcinoma: identification of risk categories according to fat infiltration and renal vein thrombosis. Clin Genitourin Cancer 11(4): 451-457, 2013. PMID: 23816525. DOI: 10.1016/j.clgc.2013.05.006

10 Shah PH, Lyon TD, Lohse CM, Cheville JC, Leibovich BC, Boorjian SA and Thompson RH: Prognostic evaluation of perinephric fat, renal sinus fat, and renal vein invasion for patients with pathological stage T3a clear-cell renal cell carcinoma. BJU Int 123(2): 270-276, 2019. PMID: 30113768. DOI: $10.1111 /$ bju.14523

11 Novara G, Ficarra V, Antonelli A, Artibani W, Bertini R, Carini M, Cosciani Cunico S, Imbimbo $\mathrm{C}$, Longo $\mathrm{N}$, Martignoni $\mathrm{G}$, Martorana G, Minervini A, Mirone V, Montorsi F, Schiavina R, Simeone C, Serni S, Simonato A, Siracusano S, Volpe A and Carmignani G: Validation of the 2009 TNM version in a large multi-institutional cohort of patients treated for renal cell carcinoma: are further improvements needed? Eur Urol 58(4): 588595, 2010. PMID: 20674150. DOI: 10.1016/j.eururo.2010.07.006

12 Jung SJ, Ro JY, Truong LD, Ayala AG and Shen SS: Reappraisal of T3N0/NxM0 renal cell carcinoma: significance of extent of fat invasion, renal vein invasion, and adrenal invasion. Hum Pathol 39(11): 1689-1694, 2008. PMID: 18656240. DOI: 10.1016/j.humpath.2008.04.011

13 Zini L, Destrieux-Garnier L, Leroy X, Villers A, Haulon S, Lemaitre L and Koussa M: Renal vein ostium wall invasion of renal cell carcinoma with an inferior vena cava tumor thrombus: prediction by renal and vena caval vein diameters and prognostic significance. J Urol 179(2): 450-454, 2008 PMID: 18076946. DOI: $10.1016 /$ j.juro.2007.09.042

14 Rodriguez Faba O, Linares E, Tilki D, Capitanio U, Evans CP, Montorsi F, Martínez-Salamanca JI, Libertino J, Gontero P and Palou J: Impact of microscopic wall Invasion of the renal vein or inferior vena cava on cancer-specific survival in patients with renal cell carcinoma and tumor thrombus: A multi-institutional analysis from the international renal cell carcinoma-venous thrombus consortium. Eur Urol Focus 4(3): 435-441, 2018. PMID: 28753848. DOI: 10.1016/j.euf.2017.01.009

15 Roberts WW, Bhayani SB, Allaf ME, Chan TY, Kavoussi LR and Jarrett TW: Pathological stage does not alter the prognosis for renal lesions determined to be stage $\mathrm{T} 1$ by computerized tomography. J Urol 173(3): 713-715, 2005. PMID: 15711249. DOI: $10.1097 / 01 . j u .0000153638 .15018 .58$

16 Oh JJ, Byun SS, Lee SE, Hong SK, Lee ES, Kim HH, Kwak C, $\mathrm{Ku}$ JH, Jeong CW, Kim YJ, Kang SH and Hong SH: Partial nephrectomy versus radical nephrectomy for non-metastatic pathological T3a renal cell carcinoma: a multi-institutional comparative analysis. Int J Urol 21(4): 352-357, 2014. PMID: 24118633. DOI: $10.1111 /$ iju.12283

17 Gilbert SM, Murphy AM and Katz AE, Goluboff ET, Sawczuk IS, Olsson CA, Benson MC and McKiernan JM: Reevaluation of TNM staging of renal cortical tumors: recurrence and survival for T1N0M0 and T3aN0M0 tumors are equivalent. Urology 68(2): 287-291, 2006. PMID: 16904438. DOI: 10.1016/ j.urology.2006.02.012

18 Russell CM, Lebastchi AH, Chipollini J, Niemann A, Mehra R, Morgan TM, Miller DC, Palapattu GS, Hafez KS, Sexton WJ, Spiess PE and Weizer AZ: Multi-institutional survival analysis of incidental pathologic T3a upstaging in clinical T1 renal cell carcinoma following partial nephrectomy. Urology 117: 95-100, 2018. PMID: 29678662. DOI: 10.1016/j.urology.2018.04.002 
19 Lai GS, Li JR, Wang SS, Chen CS, Yang CK, Hung SC, Cheng $\mathrm{CL}, \mathrm{Ou}$ YC and Chiu KY: Survival analysis of pathological T3a upstaging in clinical T1 renal cell carcinoma. In Vivo 34(2): 799-805, 2020. PMID: 32111787. DOI: 10.21873/invivo.11841

20 Jeon HG, Jeong IG, Kwak C, Kim HH, Lee SE and Lee E: Reevaluation of renal cell carcinoma and perirenal fat invasion only. J Urol 182(5): 2137-2143, 2009. PMID: 19758661. DOI: $10.1016 /$ j.juro.2009.07.065

21 Yoo C, Song C, Hong JH, Kim CS and Ahn H: Prognostic significance of perinephric fat infiltration and tumor size in renal cell carcinoma. J Urol 180(2): 486-491, 2008. PMID: 18550101. DOI: $10.1016 /$ j.juro.2008.04.034

22 Ravaud A, Motzer RJ, Pandha HS, George DJ, Pantuck AJ, Patel A, Chang YH, Escudier B, Donskov F, Magheli A, Carteni G, Laguerre B, Tomczak P, Breza J, Gerletti P, Lechuga M, Lin X, Martini JF, Ramaswamy K, Casey M and Staehler M, Patard JJ and S-TRAC Investigators: Adjuvant sunitinib in high-risk renalcell carcinoma after nephrectomy. N Engl J Med 375(23): 22462254, 2016. PMID: 27718781. DOI: 10.1056/NEJMoa1611406

23 Ueda K, Suekane S, Hirano T, Ogasawara N, Chikui K, Uemura K, Nakiri M, Nishihara K, Matsuo M and Igawa T: Efficacy of axitinib as second-line treatment in locally advanced and metastatic renal cell carcinoma. Anticancer Res 38(9): 53875392, 2018. PMID: 30194193. DOI: 10.21873/anticanres.12868
24 Bozkurt O, Inanc M, Hacibekıroglu I, Esbah O, Seker M, Ulas A, Aydin K, Uysal M, Kücüköner M, Uncu D, Cıltas A, Unal OÜ, Durnali A, Demırcı U, Berk V, Tonyali O, Oksüzoglu B, Karaca $\mathrm{H}$ and Ozkan M: Clinicopathological characteristics and prognosis of patients according to recurrence time after radical nephrectomy for localized renal cell carcinoma: a multicenter study of Anatolian Society of Medical Oncology (ASMO). Anticancer Res 34(8): 4463-4470, 2014. PMID: 25075086.

25 Jang NR, Baek J, Ko Y, Song PH and Gu MJ: High MCM6 expression as a potential prognostic marker in clear-cell renal cell carcinoma. In Vivo 35(1): 299-306, 2021. PMID: 33402477. DOI: 10.21873/invivo.12259
Received December 8, 2020

Revised January 15, 2021

Accepted January 18, 2021 